\title{
Progress in the development of the semi-empirical calibration of neutron probes based on Monte Carlo modeling
}

\author{
Urszula Woźnicka \\ Institute of Nuclear Physics Polish Academy of Sciences; ul. Radzikowskiego 152, 31-342 Kraków, Poland; \\ e-mail: Urszula.Woznicka@if.edu.pl; ORCID ID: 0000-0001-7023-9074
}

(C) 2020 Author. This is an open access publication, which can be used, distributed and reproduced in any medium according to the Creative Commons CC-BY 4.0 License requiring that the original work has been properly cited.

Received: 3 December 2020; accepted: 15 December 2020; first published online: 28 December 2020

\begin{abstract}
The method of the semi-empirical calibration of a neutron well logging probe was developed by Jan Andrzej Czubek on the concept of the general neutron parameter (GNP) and tested positively at the neutron calibration station in Zielona Góra, Poland. The neutron probe responses in a wide range of neutron parameters (and thus lithology, porosity and saturation) were also computed using the Monte Carlo method. The obtained simulation results made it possible to determine the calibration curves using the Czubek concept in a wider range than by means of the original method. The very good compatibility of both methods confirms the applicability of the GNP as well as the Monte Carlo numerical experiments, which allow for a significant extension of the semi-empirical calibration in complex well geometries taking into account e.g., casing or invaded zones.
\end{abstract}

Keywords: neutron well logging, calibration of the borehole neutron probe, general neutron parameter of neutron transport

\section{INTRODUCTION}

The basis of neutron measurements in borehole geophysics is the registration of the neutron flux emitted by the neutron source towards the measured rock medium. Both the neutron source and the detector are placed in a probe located in the borehole. The purpose of such measurement is to obtain quantitative data on selected petrophysical parameters of a given rock formation, mainly porosity. The main interpretation problem of the measurement is the fact that the neutron flux reaching the detector (i.e., the detector response) does not directly and unambiguously correlate with the porosity of the medium under investigation. This is due to the physical phenomenon of neutron transport in the medium. This phenomenon is based on inelastic and elastic scattering of neutrons on the nuclei of atoms in the environment until it is absorbed by the subsequent nucleus. The detector counts those neutrons which, after a few scattering acts, reached the active volume of the detector and were absorbed in it. This means that the detector response correlates with the integral parameters of scattering and absorption of neutrons by the medium, and only in the next step can be correlated with selected petrophysical parameters. This sequence of interpretation of neutron profiling is presented by the semi-empirical method of calibrating neutron probes introduced by Jan Andrzej Czubek (Czubek 1994a). The detector response is correlated with the so-called general neutron parameter $(G N P)$ and then, GNP is correlated e.g., with porosity of the medium with known lithology. 
The general neutron parameter introduced by Czubek is based on analytical solutions of neutron transport equations in terms of two neutron energy groups (fast and thermal neutrons) in a simple cylindrical borehole geometry. Currently, this theory has been verified with a precise Monte Carlo numerical experiment. It is shown below that the new numerical calculations confirm that the general neutron parameter can play the role of a comprehensive physical parameter of the medium in which the neutron transport phenomenon occurs. Also, the semi-empirical method of calibrating neutron probes can be further developed for more complex geometries than in the original version of Czubek.

\section{INTEGRAL NEUTRON TRANSPORT PARAMETERS OF MEDIUM}

Neutron sources used in geophysical probes are sources of fast neutrons. The average energy of neutrons emitted by the AmBe isotope source is 4.5 MeV, while in the case of a neutron generator with a deuterium-tritium source it is about $14 \mathrm{MeV}$. The parameters of the medium in which the neutron transport phenomenon takes place depend on the energy of the neutrons. In macroscopic terms, i.e., for volume media, we define the following basic integral parameters: the slowing down length $L_{s}$, the diffusion length $L_{d}$ and the absorption cross section of thermal neutrons $S_{a}$.

The fast neutron slowing down length, $L_{s}$, is defined as the average length that the neutron travels from the source until it reaches the thermal energy, i.e., about $0.025 \mathrm{eV}$ (Czubek 1990):

$L_{s}^{2}=\frac{1}{6} \frac{\int_{V} \Phi_{f}(\vec{r}) r^{2} d V}{\int_{V} \Phi_{f}(\vec{r}) d V}$

The fast neutron flux $\Phi_{f}(\vec{r})$ is integrated over the entire volume $V$ of the medium in which the neutron scattering occurs. The diffusion length, $L_{d}$, which is the average distance of the thermal neutron travel to the point where it is absorbed, is defined similarly. The basic definition of these parameters is the case where a point neutron source is placed in an infinite homogeneous medium ( $\vec{r}$ is the distance of the scattered neutron from the source). The function of neutron flux can be calculated analytically from the differential-integral Boltzmann transport equation, which is only possible in the case of significant simplifications in the energy variability of the neutron flux and spatial boundary conditions.

Czubek presented analytical solutions allowing the determination of the slowing down and diffusion lengths in cylindrical borehole geometry. These solutions allowed the determination of the correlation between the response of the neutron probe detector, $N$, and the so-called general neutron parameter, GNP (Czubek 1994a, Woźnicka et al. 2018), expressed as a function:

$N=f(G N P)$, where $G N P=f\left(L_{s-a p}, L_{d-a p}, S_{a-a p}\right)$

The neutron parameters $L_{s-a p}$ and $L_{d-a p}$ were calculated based on the approximate solution of the neutron transport equations in the geometry of a cylindrical borehole with a radius $R$ and infinite length surrounded by an infinite rock formation. The absorption cross section $S_{a-a p}$ was determined on the basis of the weighted average number of neutrons absorbed in the rock formation and in the borehole. The differences between the values of the parameters determined for the infinite medium and those calculated for the specific borehole geometry system are significant. Table 1 shows the example for the Miocene of the Carpathian foothills $\left(\mathrm{SiO}_{2} 72.5 \%\right.$, $\mathrm{Al}_{2} \mathrm{O}_{3} 7.0 \%, \mathrm{Fe}_{2} \mathrm{O}_{3} 2.0 \%, \mathrm{CaO} 7.5 \%, \mathrm{~K}_{2} \mathrm{O} 1.8 \%$, $\mathrm{H}_{2} \mathrm{O} 1.2 \%, \mathrm{CO}_{2} 8.0 \%,{ }^{10} \mathrm{~B} 0.00163 \%$, porosity $5 \%$, density $2.63 \mathrm{~g} / \mathrm{cm}^{3}$, pore saturation $100 \% \mathrm{H}_{2} \mathrm{O}$ ), assuming that the borehole has a diameter of $216 \mathrm{~mm}$ and is filled with water, and the source of the neutrons is AmBe.

\section{Table 1}

Integral neutron parameters for an infinite medium and for borehole cylindrical geometry. Example for the Miocene of the Carpathian foothills

\begin{tabular}{|c|c|c|}
\hline$L_{s}=15.70 \mathrm{~cm}$ & $L_{d}=8.01 \mathrm{~cm}$ & $\Sigma_{a}=12.27$ c.u. \\
\hline$L_{\text {s-ap }}=12.05 \mathrm{~cm}$ & $L_{d-a p}=4.10 \mathrm{~cm}$ & $\Sigma_{\text {a-ap }}=14.55 \mathrm{~cm}$ \\
\hline
\end{tabular}

The applications of Czubek's calibration method have been published widely (e.g., Czubek 1994b, 1995). The example (Tab. 1) clearly shows 
that the neutron probe response should be correlated with the neutron parameters calculated for the specific measurement geometry, and not with the material parameters for infinite media. However, it should be remembered that Czubek's solutions concern the simplest two-zone cylindrical geometry of the borehole-rock formation. Further development of this method is possible using Monte Carlo modeling.

\section{APPLICABILITY OF THE GENERAL NEUTRON PARAMETER}

Modern computational methods allow for reliable numerical simulations of neutron transport in any medium. The Monte Carlo calculations of neutron probe responses carried out by the IFJ PAN team were successfully verified by comparison with the real measurements made in real borehole conditions (Wiącek \& Woźnicka 2016).

The range of the variability of the neutron parameters of rock formations for which the numerical calculations of the probe responses were performed is much wider than that used when testing Czubek's method discussed above (Tab. 2). Using the results of numerical calculations obtained, it was possible to determine the calibration curve $N(G N P)$ and confront it with Czubek's earlier results. Figure 1 shows the calibration curve of a neutron probe constructed on the basis of all the results, both analytical solutions verified at the probe calibration station in Zielona Góra and the results of numerical calculations.

Table 2

The range of the variability of porosity and neutron parameters of the media used in numerical experiments for neutron probes. In parentheses are given the parameter values used in the Czubek method tests

\begin{tabular}{|l|c|c|}
\hline \multicolumn{1}{|c|}{ Parameter } & Min value & Max value \\
\hline Porosity [\%] & $0(0.1)$ & $90(59.72)$ \\
\hline Slowing down length $L_{s}[\mathrm{~cm}]$ & $7.42(9.49)$ & $17.14(16.32)$ \\
\hline $\begin{array}{l}\text { Thermal neutron diffusion } \\
\text { length } L_{d}[\mathrm{~cm}]\end{array}$ & $2.56(2.56)$ & $8.98(8.98)$ \\
\hline $\begin{array}{l}\text { Thermal neutron absorption } \\
\text { cross section } \Sigma_{a} \text { [c.u.] }\end{array}$ & $5.72(5.72)$ & $29.18(13.04)$ \\
\hline
\end{tabular}

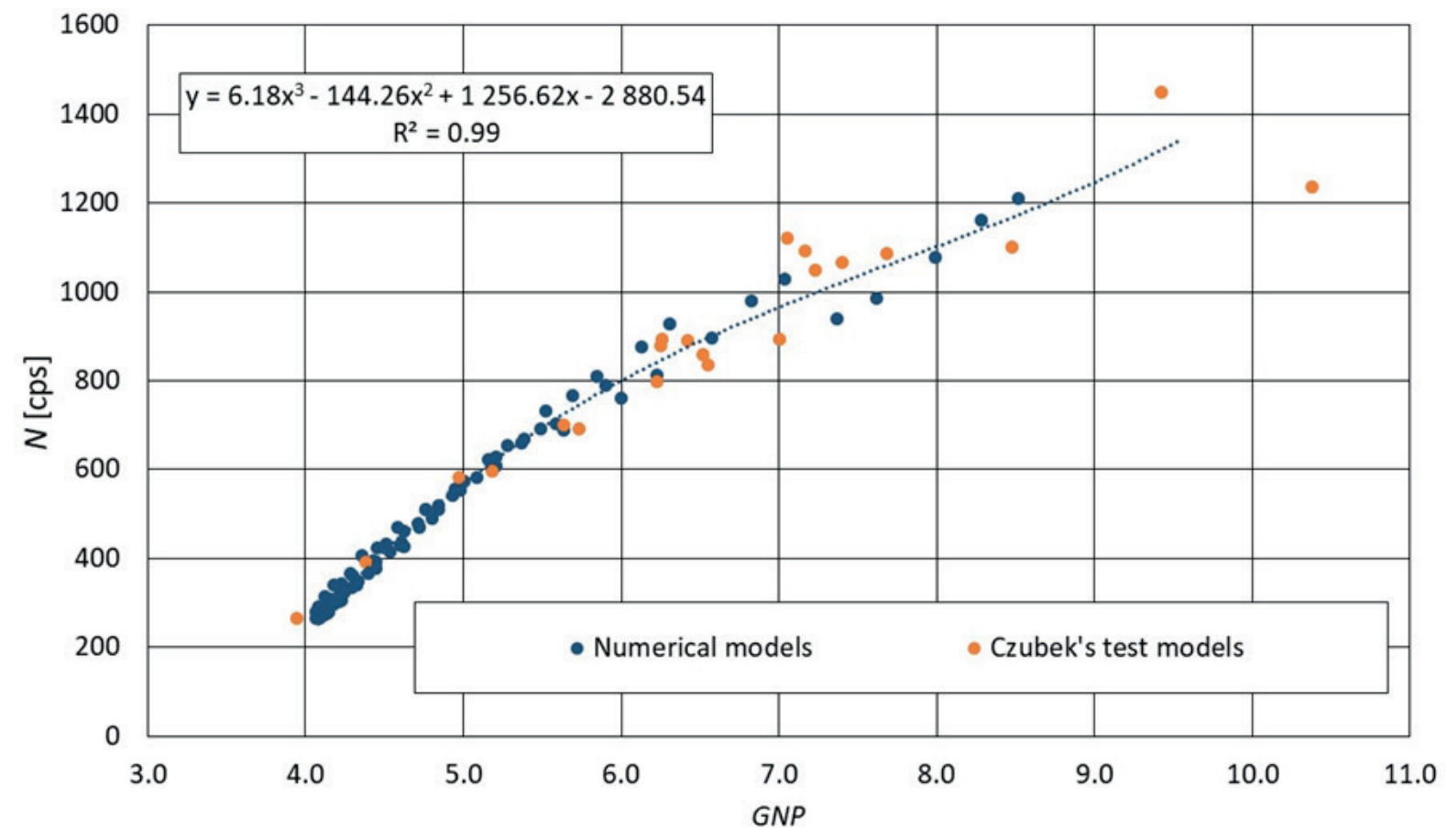

Fig. 1. Semi-empirical calibration curve of the neutron probe resulting from Czubek's test models (blocks of the calibration station in Zielona Góra, Poland) and on the results of numerical calculations (on the basis of Woźnicka \& Wiacek 2018) 
The very good agreement of the position of all points on the curve confirms the applicability of the general neutron parameter in the semi-empirical method of calibrating the neutron probe. This consistency also ensures the further validation of the Monte Carlo numerical methods used to simulate the responses of neutron probes.

\section{CONCLUSIONS}

The presented results confirm the physical correctness and applicability of the general neutron parameter in solving the problem of neutron transport in heterogeneous media. This parameter was proposed by Czubek for the simplest case of a borehole-formation geometry. Currently, we can extend the application of the GNP concept and the semi-empirical method of neutron probe calibration to more complicated geometry systems using numerical methods, e.g., taking into account invaded zones or borehole casing.

\section{REFERENCES}

Czubek J.A., 1990. Rock Neutron Parameters - I. Neutron Slowing-Down Parameters. Nuclear Geophysics, 4(2), 143-167.

Czubek J.A., 1994a. Neutron Tool Calibration by a Scaling Procedure. Nuclear Geophysics, 8(3), 261-279.

Czubek J.A., 1994b. Metodyka i oprogramowanie semiempirycznej metody kalibracji sond neutronowych. Geologia: kwartalnik Akademii Górniczo-Hutniczej im. Stanisława Staszica w Krakowie, 20, 2, 121-146.

Czubek J.A., Ossowski A., Zorski T. \& Massalski T., 1995. Rock models at Zielona Góra (Poland) applied to the semi-empirical neutron tool calibration. Nuclear Geophysics, 9(6), 517-531.

Wiącek U. \& Woźnicka U., 2016. Feasibility of Monte Carlo modelling for the neutron-neutron logging tool response in specific geological models. Geology, Geophysics \& Environment, 42, 3, 365-383. https://dx.doi.org/10.7494/geol.2016.42.3.365.

Woźnicka U. \& Wiącek U., 2018. Weryfikacja Monte Carlo półempirycznej metody kalibracji otworowych sond neutronowych. [in:] Rozwój technik poszukiwania i eksploatacji złóż węglowodorów: Geopetrol 2018: materiały konferencyjne = Development of hydrocarbon exploration and production technologies, Instytut Nafty i Gazu, Państwowy Instytut Badawczy, Kraków, 243-247.

Woźnicka U., Wiącek U. \& Dworak D., 2018. Amplitude degradation of thin layer in neutron logging. Applied Radiation and Isotopes, 142, 211-219. https://doi.org/10.1016/j.apradiso. 2018.08.017. 